\title{
Ask Them: Child Participation in the Development of Educational Services
}

\author{
Manuel Finelli \\ Emilia-Romagna Regional Agency for Social and Health Care \\ Claudia Rocca, Valentina Marchesi, Stefania Maggi \\ Institute of Interdisciplinary Studies, Carleton University
}

\begin{abstract}
In accordance with Article 12 of the United Nations Convention on the Right of the Child (UNCRC), we conducted a consultation process with 113 children between four and seven years of age from five different schools in Italy. We asked children to imagine their ideal school in guided conversations, drawings, and drawing descriptions. Their responses were organised into three thematic areas: (a) school quality, (b) purposes of early childhood education, and (c) activities to include in the school curriculum. Consistent with literature on participatory research, this six-month consultation process demonstrates that even young children's views can be useful to policy-making. Particular attention is given to the methodology.
\end{abstract}

Keywords: School quality, educational programme development, child rights-based approach, child participation, early childhood educational services, preschool children

\section{Introduction}

Until a few years ago, asking children for their opinion in studies concerning city bylaws and regulations was rare. When children were consulted, they were asked to report on matters that concerned them personally, such as self-identity (Winstone et al, 2014), paediatric oncology (Johnson et al. 2011) or care services (Hill, 1995). It was only after the 
General Comment (No. 7) released by the United Nations Committee on the Rights of the Child (UNCRC) that the views of children, even those of a very young age, started to be taken into account. According to the UNCRC, child participation is a legally binding duty that signatory countries must respect and promote. Acknowledging that children have rights means recognizing them as citizens, social actors and members of society who can contribute to its development (IAWGCP, 2008). Article 12 of the UNCRC states, "all girls and boys have the right to express their views and opinions on matters that affect them, and to have those views and opinions taken into account" (page number?)

Since the UNCRC declaration, researchers have taken up the task of attending to children's participation in the research process by consulting children on issues ranging from education (Fielding, 2001; Kellet et al., 2004; Jaeger et al., 2004; Dhakal, 2010), race and gender equity (MacNaughton, $2001 \mathrm{a}, \mathrm{b}, \mathrm{c}$ ), violence (Lansdown, 2005) and children's rights (Allan and L'anson, 2004). Many of these studies, including those that have involved very young children, have demonstrated that children are capable of offering valuable insights.

Recently, MacNaughton, Hughes and Smith (2007) presented two case studies showing how consulting very young children can contribute to policy-making and the wider community. This was the first time in Australia that the voices of young children were formally included at the level of governmental decision making (territorial and state government). In their research, MacNaughton, Hughes and Smith (2007) asked children to report on wellbeing and how gender affects learning and relationships through drawings. Drawing is considered one of the most appropriate methods when working with children, especially when they are very young (James et al. 1998:189).

The goal of our study was to understand children's perceptions of the characteristics and purposes of their schools. We asked young children to imagine their ideal school through guided conversations, drawings, and drawing descriptions. Their opinions were included in a process of policy-making consultation that took place in Italy. Below we describe the process and results.

\section{Methods}

In 2013, the City of Bologna, Italy, developed a set of guidelines (the "Service Charter") to create educational programs and policies for the early years. Consistent with its tradition in using participatory processes, the City of Bologna included at the working table the input of several representatives of the community and its stakeholders: teachers, parents and, for the first time, children. To conduct the consultations with the children, the City hired 
a facilitator consultant who was hired by the municipality of Bologna as an expert in using participatory methods with children.

In total, five teachers and 113 children between the age of four and seven participated in the consultation. The facilitator, assisted by the teachers, organized a series of consultations with pre-school and elementary school children. The consultation protocol was approved by the schools and integrated into the school curriculum. The consultation was considered by the schools to be consistent with the curriculum and for this reason, applied the parental consent obtained at the beginning of the school year. Children were asked for their assent to participate before starting the activities.

The study took place in five schools in the City of Bologna - two pre-schools and three elementary schools. The participating schools were identified based on the availability of the teachers and their previous experience in child-participatory studies.

\section{Procedure}

\section{The "introd-action" meeting}

Prior to beginning the consultation, the facilitator held a meeting with the teachers. The meeting served to help refine the methodology to best suit the unique context of each classroom and to support the teachers as they prepared for the consultation.

The meeting with the teachers was divided into two sections. During the first section, the facilitator discussed children's participation as a human right. The second section focused on discussing the following themes: human rights versus 'social nobody-ness' of children; The United Nations Convention on the Rights of the Child; diversity and participation; and specific requirements to effectively support children's participation as well as the methodology described below.

\section{The Consultation Process}

Four activities comprise the study: The Circle of Children, The Circles of Worlds, The School I Like, and The Circle of Ideas.

The Circle of Children activity was meant to familiarize children with the presence of the facilitator. To achieve this goal, the facilitator used an African rag doll which he introduced as his friend. The activity required children to say their name by passing the doll to the next child in the circle. The African rag doll was used in four schools. In the fifth 
school the teacher suggested the use of a "magic wooden stick" that the children passed around (see Illustration 1).

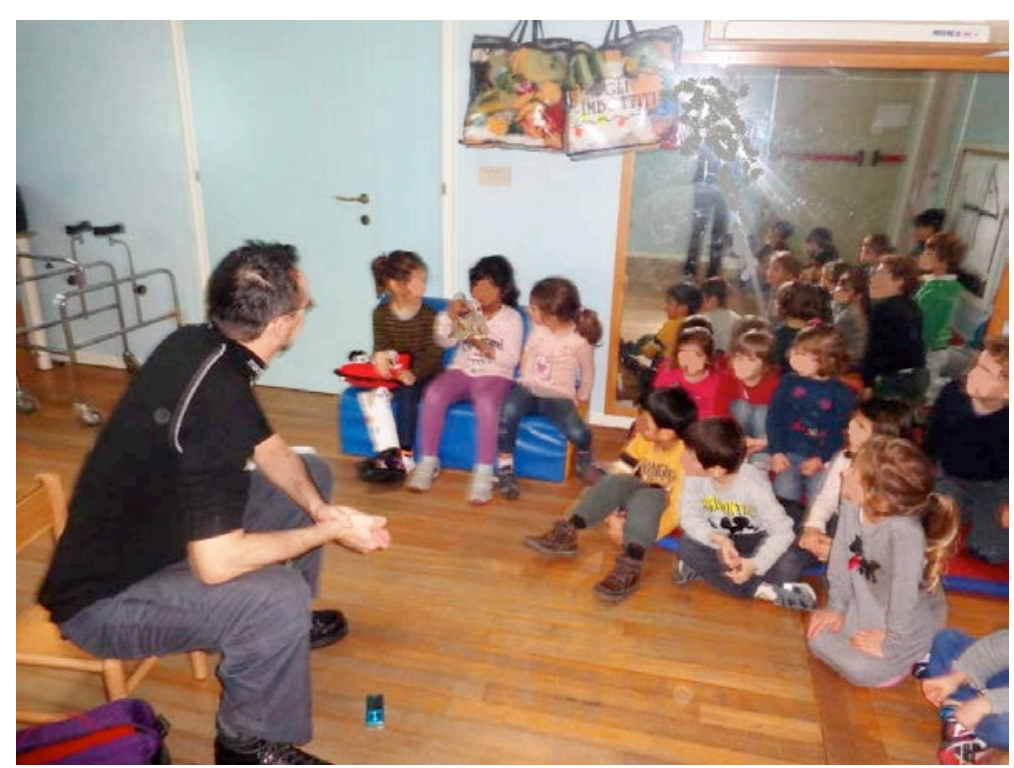

Illustration 1 - The Circle of Children... getting to know each other

The Circle of Worlds activity was meant to understand the perception children have of schools in general. To this end, the facilitator showed four sets of photos portraying children and school buildings from around the world. The photos were printed on A4 coloured paper and laminated (see Illustration 2).

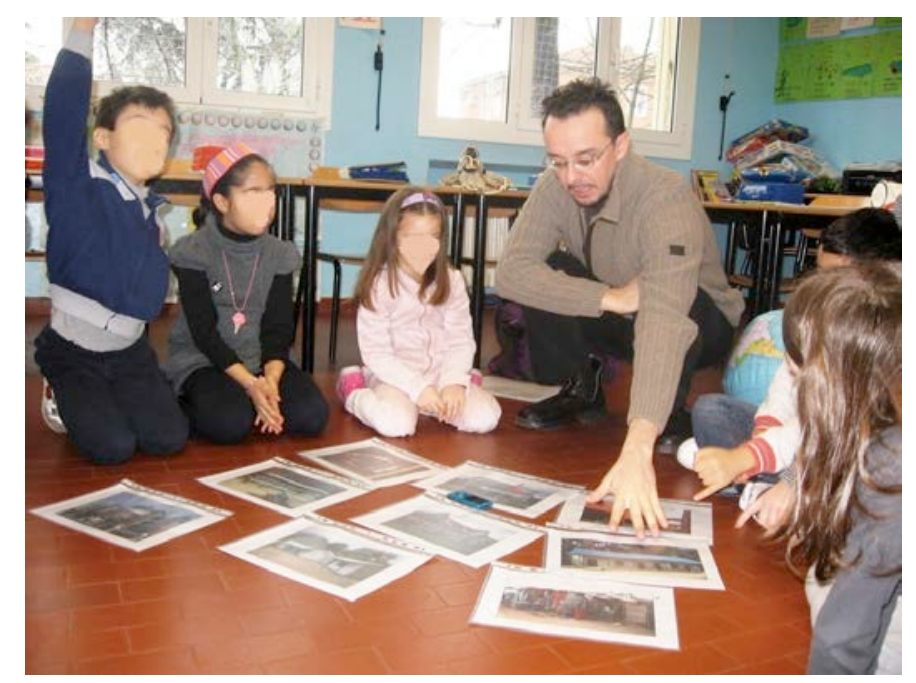

Illustration 2 - The Circle of Worlds... understanding children's perception of schools 
The first set of photos titled "Children around the world" portrayed children at play in different parts of the world. The second set, "Schools of the World," portrayed photos of school buildings from different parts of the world. The different sets of photos served to gradually engage the children from talking about playing to talking about school.

The third set of photos titled "Buildings around the world" was accompanied by the following questions: "Which of these buildings is a school"? and "what images struck you the most about this photo and why"? To complement the activity, the facilitator showed a fourth and last set of photos portraying different classroom settings. The photos also showed teachers and students and served as prompts to further engage children in conversations about peers and educators.

The School I Like activity involved collecting children's perceptions through the use of drawings and their descriptions. The facilitator asked the children to make two drawings: one to illustrate an ideal school and the other to illustrate the type of activities children would like to do in school. The questions were as follows: 1) "How would you like your school to be"? and 2) "What activities would you like to do in your school”? Children six years and older were also asked to respond to the questions in writing with a short sentence (see Illustration 3).

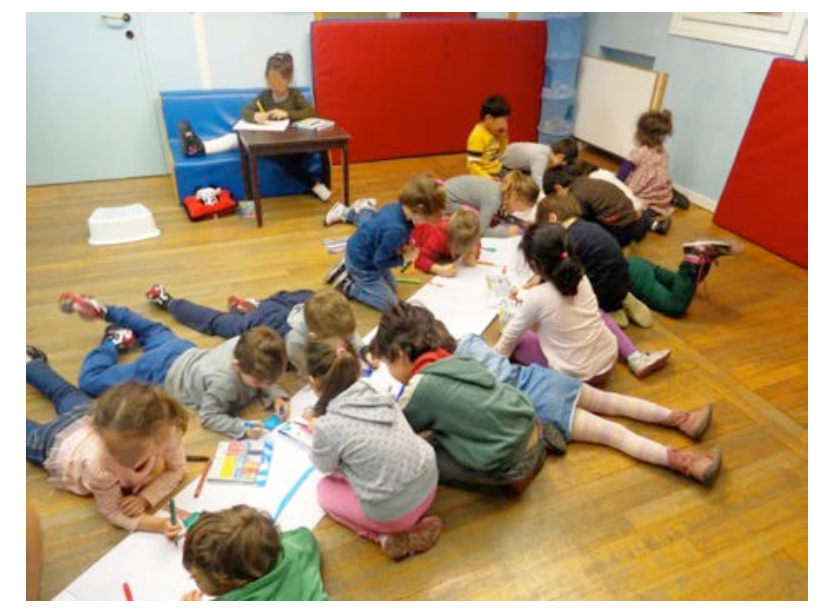

Illustration 3 - The school I like... individual drawing session

The circle of ideas activity involved asking children to describe their drawings. Once the drawings were completed, the facilitator asked children to place them on a panel he had previously placed on the floor. Once the drawings had been placed on the panel, the children were asked to stand in a semi-circle around it. The facilitator taped and glued the drawings on the panel giving children the choice to decide where on the panel they wanted to position 
their drawings. Each child then described his or her drawing to the facilitator and classmates (Illustration 4).

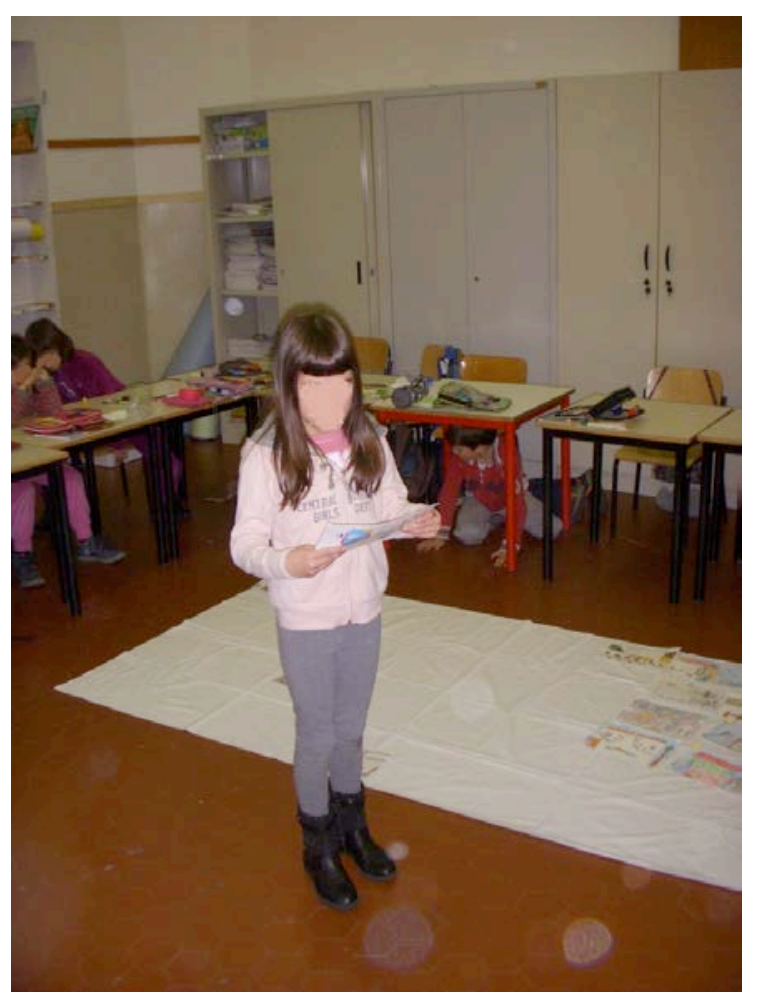

Illustration 4 - The circle of ideas... describing the drawings content

\section{Results}

Exploratory content analysis was undertaken on transcripts of the children's responses and observations of the drawings. The facilitator conducted the analysis by reading each response and recording themes as they emerged. These themes were then consolidated into three general categories: school quality; purpose of early childhood education; and activities to include in the school curriculum.

The first category, school quality, consisted of responses children gave about the physical features of a school. The second category, purposes of early childhood education, consisted of responses related to teachers' characteristics and peer relationships. And the final category, activities to include in the school curriculum, consisted of responses children gave relating to activities to include in the school curriculum. The comments of students reported below are translated from Italian. 


\section{School quality}

Analysis of the audio-recordings and drawings for school quality provided three different sub-areas: Spatial dimensions, colours and nature (Illustration 5).

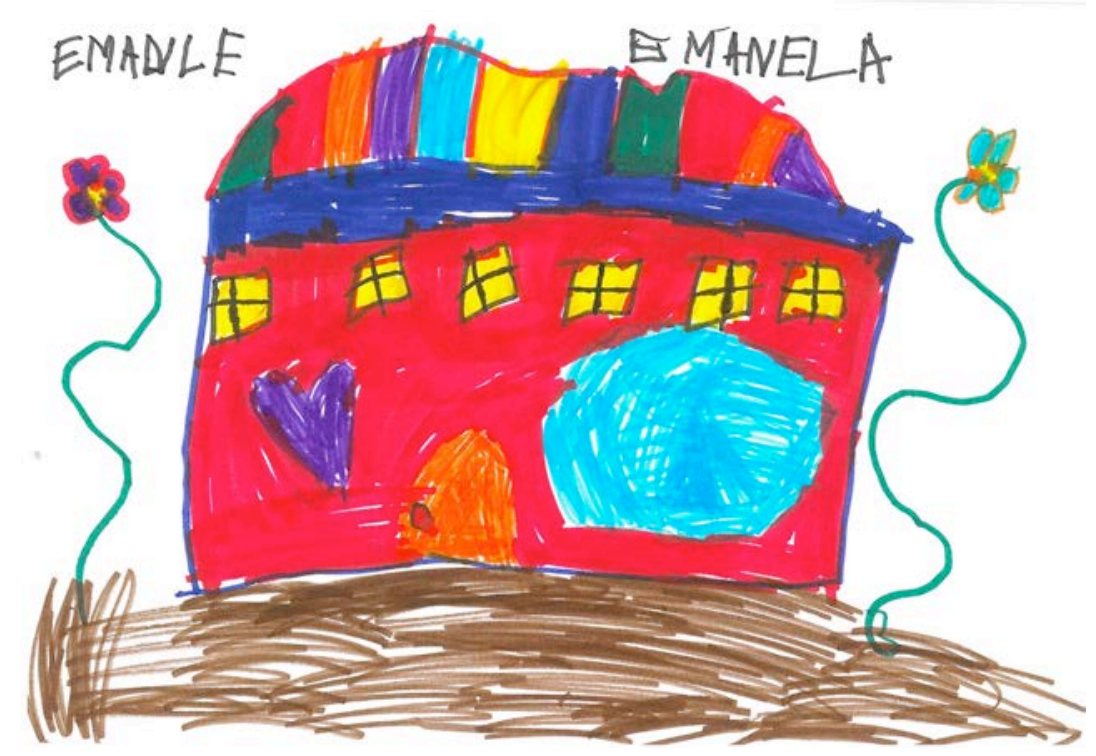

Illustration 5 - Quality: spatial dimension, colours and nature

\section{Spatial dimensions}

Children linked school quality to the size of its premises. They suggested that a desirable school should have multiple floors, big windows and large spaces to move around and play. One student, for example, suggested that, "Pretty schools are those having more floors because there is more space for us." Another student said, "A classroom is pretty when it is big enough for us to play in it."

The size of the school appeared to be essential to guarantee space for everyone. Representative comments included the following: "In a big school there is room for children running together," "... There is space to play all together" and "It is nice to have a space indoor to play together." "The school must be big enough to welcome all children of the world and "the school must be big, because the more we are, the more friends we can make" are two quotes indicating how large spaces are not only important to define the quality of the school but also make it possible to accommodate many children. Children emphasized the importance of spending time with other children.

Additionally, the layout of the classroom was considered to be important. Most children favoured U-shaped arrangement of the desks to the more conventional classroom layout made up of rows of desks facing the teacher's desk: "I would like my classroom with 
desks all nearby, so that we all can see better." "I like the way we have it: with big desks put in a circle." "I like a classroom in which the desks are assembled in groups: it is nice to be sitting in small circles."

Younger children went a step further by proposing castle-like buildings, with knights, dragons and fairies. As one child stated,"the school I want is a bit strange, but sometimes we

all need fantasy too!" According to these children, a school should be large enough to accommodate magic and imagination: "I make a drawing of a classroom, yet it is not the one I stay in. This is the classroom I would like, the classroom of my imagination."

\section{Colours}

Colourful classrooms were also central aspect of school quality, especially for the younger children (age 4 to 5). "Plenty of colours make the school prettier."

Colours glimmering out of flags, as well as painted walls, doors and windows all filled with drawings and glowingly whitewashed. Children commented on the relevance of colours and drawings as important aspects of a school.

\section{Nature}

Most children made drawings of a school surrounded by green spaces, trees and flowers. They described schoolyards covered with grass and big enough to play soccer in. This is what some of the children said: "There is a lot of nature in the premises." "There is a lawn and children can stay outdoor." "There are plenty of trees, including palms!" "There are trees and nearby mountains." "(In school) I love greenery!" "In the school I like there are children playing soccer, and I like to play outside." "There is a big garden." "There is a forest close by." "There are plenty of flowers and plants." "I love grass and trees!"

Overall, children identified the following elements as contributing to the quality of a school: ample dimensions, large spaces to share with, colourful classrooms, large outdoors spaces and room for fantasy and imagination.

\section{Purposes of early childhood education}

This category was characterized by three sub-themes: happiness, supportive learning environment and friendship (Illustration 6). 


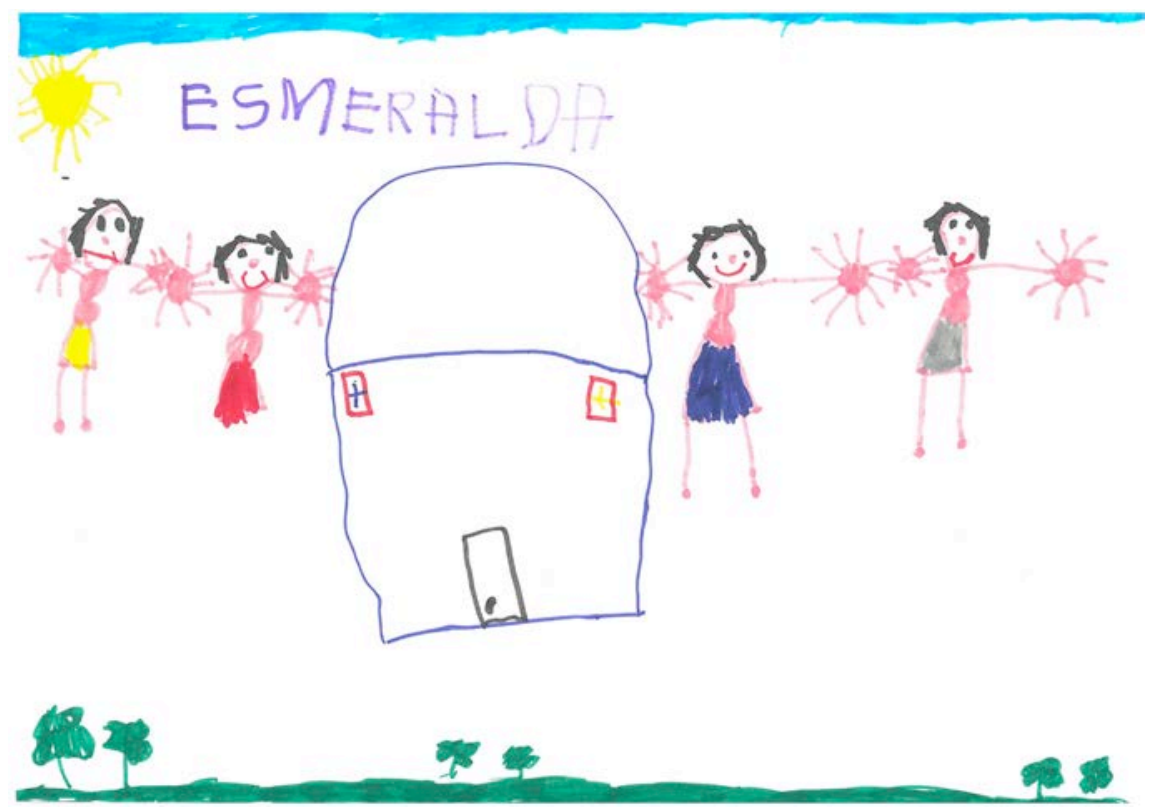

Illustration 6 - Purposes of education: Happiness, Learning Environment, and Friendship

\section{Happiness}

The majority of children, associating the concept of happiness to comfort and security, considered children's wellbeing as a priority schools should strive for. This is what emerged from some of the children descriptions: "The school is merrier if children are happy." "I like a school that makes children happy; for instance, we are lucky children because we have a nice school." Some children perceived the school as the place in which "There is all we need. That is why we are happy." "Children are happy." "Children smile."

\section{Supportive learning environment}

Most children considered learning to be a very important aspect of school. This is what emerged from the descriptions of the drawings from several children: "When the school is ugly, the teacher has to be a good teacher." This quote strengthens the idea of a school offering an effective learning environment. Others include:

"The prettiest thing (in school) is that we learn new things." "In the school (I would like) the children to have to be able to learn well." "I like a school where children study happily." "School is important because we can study and learn in there." "I like my school because I learn in it." "The most beautiful thing in school is that we learn new things." "We learn new things everyday." "Every day we learn and we play." 
Children attributed considerable importance to their learning and reflected on the ways in which their learning takes place. For instance, they valued as crucial to their learning the well being of the teachers, the administrators and support staff. This is what one child said: "I would like a teacher who is good, in the sense of sweet." "I would like a principal who sometimes wants to have fun himself too, so that we are all happy."

Children also consider relationships with adults as a vital component of schooling, especially relationships with teachers and parents. Here are some of the children's accounts:

\footnotetext{
"Teachers should educate us and not let us do all we want." "I would love to spend more time with my parents in the school, for instance having lunch together." "I would like my parents to come to school so they (the parents) can be with my friends."
}

Children expressed the need to be cared for in school in the broad sense of the term, that includes health and emotional well being. Through their drawings and the descriptions they gave of them, they reiterated that attending school goes far beyond studying and playing. Schools require services that can provide children with health and emotional support. As one child said: "I like a school which looks like a hospital because a school should always be able to help children when they are not well."

\section{Friendship}

The spontaneous capacity to care for their peers, especially for those in distress, was not underestimated by children. Many children spoke about the importance of inclusion:

\footnotetext{
"A school must be large enough, so that there is room for all the children of the world because children are all equal."
}

During the consultations, children also spoke about after school activities. These are the words of a child concerned about recycling as a way to help other children:

"If one is poor and we have pieces of fabric, we can make clothes with them. If we have small pieces of fabric, we can make clothes for dolls; with bigger pieces of fabric we could make clothes for the children who do not have any." 
Another child said:

"I like studying English so that I can have more friends. If children from other countries come to our school (in Italy) and we know how to speak English, we can talk with them and they can understand us right away."

More comments followed:

"It is nice in the morning, because children walk in together and become friends!" "At school children have fun and so they can know each other well." "I am fine in any school where I can make friends." "We must make friends at school: it is an easier thing to do there." "If you do not know anybody, going to school helps you to make friends." "The children make friends at school because they are all learning." "There must be grown-up children together with the little ones, so that when the bad guys come to beat the younger, the grown-up protect them." "The school helps children to get together at first; after that, we know and love each other."

\section{Activities to include in the school curriculum}

When asked which activities they would include in the school curriculum, children talked extensively about outdoors activities, arts \& crafts, playing, and sciences.

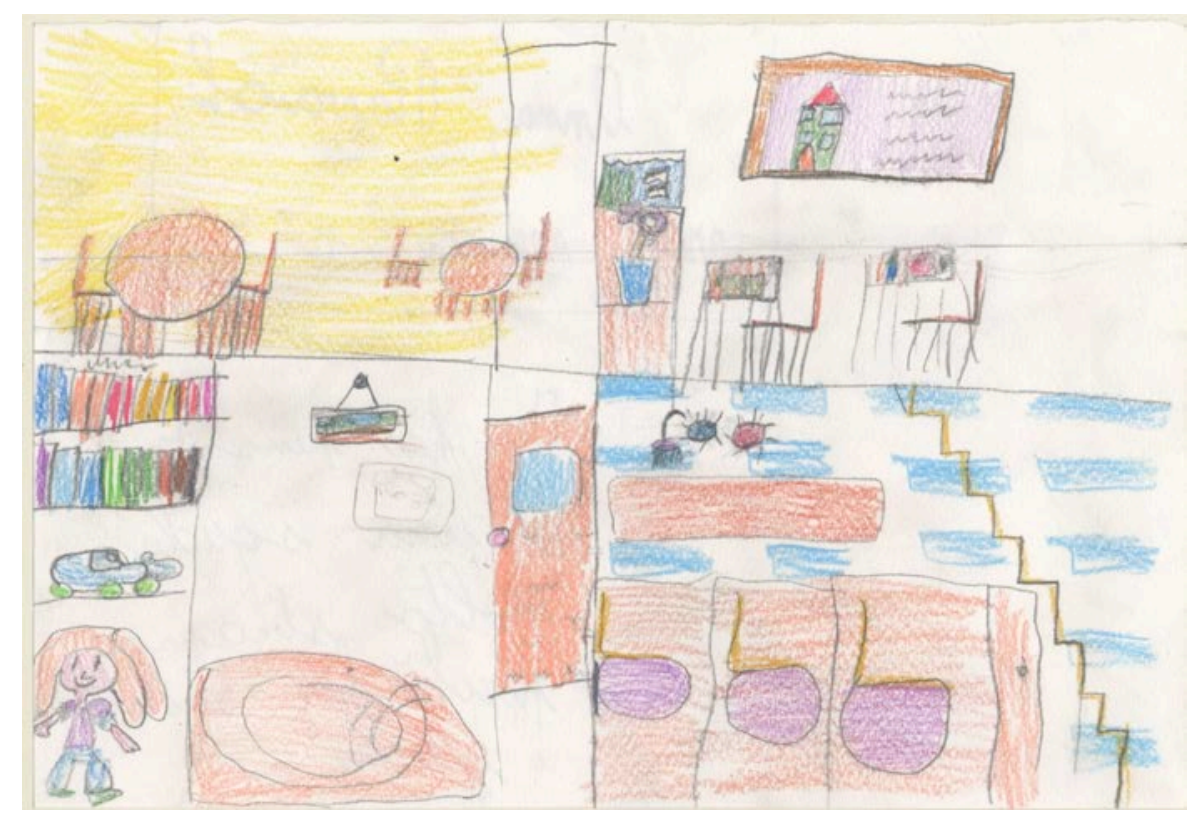

Illustration 7 - School curriculum: Outdoors activities, Arts \& crafts, Playing, and Sciences 


\title{
Outdoor activities
}

Many children described their ideal school as farm-like, with animals and vegetable gardens. These are some of the most salient descriptions from the children:

\begin{abstract}
"The school could be a kind of farm with animals placed in its different sections." "I would like to be in a school with many animals to take care of." "I want a school with a house for pets." Some children expressed the desire to grow vegetables in their ideal school "I like children growing the vegetable for the school kitchen", "Children love vegetable gardens!"
\end{abstract}

\section{Arts \& crafts}

Children's enthusiasm for plants and animals was consistent with their interest in the natural environment, as well as with an inclination towards crafting activities.

As the children described:

"I love doing craft such as making figures with paper, straws or other material."

"It's good to have time to make toys ourselves by recycling things: in this way we can give toys to the children who don't have them and so we can recycle!" "I would like a space to make new clothes with old ones." "I would like to have a lab where to make toys with trash items; because if a child is poor or he wasted his pocket money, he cannot afford to buy new toys. In this way he can have new toys too."

\section{Playing}

All of the children considered playing important. The following quotes are some of the children's descriptions:

"I like playing with puzzles, building blocks and playing games in the garden." "The school is beautiful and is absolute fun!"

These quotes stress the appreciation that children have for outdoor activities and the size of the school also remains a key factor in enabling play. Running and large spaces were cited often: "I like a big school because you can run well." "I like schools with plenty of space to do activities like theatre." 
Physical activity was emphasized both in the drawings and conversations. A group of children coming from a small school with little space, inside and outside, made drawings of soccer fields, swimming pools and parks emphasizing the importance of wide open areas.

\section{Sciences}

Children expressed significant interest in the sciences and activities related to reading and visiting museums. Sciences and reading were cited often as seen in the following quotes:

\footnotetext{
"I would like a place for the sciences and the things of the nature" "I would like to have a science-lab." Children talked about spaces for reading: "I would like a reading corner" or "a fairy-tale tent." "I like a space dedicated to reading." "I like school because we read stories." "I like school because we learn how to read."
}

Children also spoke of books they like to read including children's literature, comic books, books with cartoon characters, or illustrated books. They reported their fondness for visiting museums, listening to music, history, natural sciences, and technology. Children expressed high interest in drawing activities: "I would like a school where we can make lots of drawings." Many children proposed to use the school itself as their drawing ground. One child said: "I would like a school full of our drawings, on the walls outside, but also inside."

\section{Discussion}

The consultation revealed that many children have clear ideas about the role of the school. Their accounts contribute to the vast body of research demonstrating that young children are capable of reporting relevant information when provided with clear and detailed age appropriate tools (Christensen and Prout, 2005; Lansdown, 2005). Children in our study identified the school as a place to learn, socialize, and play. Overall, they imagined a school with large premises and colorful walls, containing a library with plenty of books, and a science lab to run experiments. They imagined a school surrounded by greenery, flowers and trees, as well as a school where caring for children and supportive teachers looked after one another, creating an environment favourable to learning. In this imaginary school, children took care of animals, grew vegetables, played, drew, and did arts \& crafts with recycled materials.

During the consultation process, children welcomed the presence of the facilitator as 
reflected in the richness of the accounts that this consultation generated. Furthermore, the drawing activity paired with descriptions of the drawings and guided conversations resulted in a plethora of information that likely could not have been obtained using drawings alone (Kress, 1997). Our consultation process distinguishes itself for its ecological validity as all activities took place in the classroom and in the presence of the teacher, respecting an environment familiar to the children.

Although we maintained children's attention with the use of puppets, photos and conversations, we need to acknowledge that presenting the activities all in one day might be too ambitious. Considering the young age of the children, it might have been more suitable to divide their activities into two or three shorter sessions to be conducted on different days.

At the time of writing of this article, the results of this consultation had not yet been integrated into the city planning. We believe, however, that consulting children about their everyday life in school, should become part of every process in matters concerning them. In recent years, the participation of children in consultation processes has shown that children have much of relevance to say. The children who participated in this consultation demonstrated a realistic view of what a school is and how it should look in order to function well.

Because children have the right to participate in decisions concerning their well being, it is important to use methodologies appropriate for their participation. We believe the methodology reported here fulfills this important function.

\section{ACKNOWLEDGEMENTS}

The City of Bologna, in particular in the person of Marilena Pillati, Deputy Mayor in charge of School and Education, should be credited for a considerable openness in supporting this project, which had to face the challenges implied by time-limitations and technical constraints. Such institutional attention would not have been raised without the internal advocacy efforts of Dino Cocchianella, Elena Iacucci and Gabriele Ventura (Municipal Administration). Sincere gratitude also goes to Professor Roberta Paltrinieri (CESCOCOM Director) to bear with the encumbering presence of the facilitator (first author) within the Group 0-6, to Marica Prandini for her invaluable aid in developing the consultation methodology, as well as to the teachers Anna Grotto, Fabiana Giuli, Letizia Tampieri, Lya Brintazzoli e Tiziana Russignan who made the consultations possible. Finally, utmost gratefulness goes to 
the children who once again brought life and truth into our professional and personal paths.

\section{References}

Allan, J. \& L'Anson, J. (2004). Children's rights in school: power, assemblies and assemblages. International Journal of Children's Rights, 12, 123-138.

Christensen P., \& Prout, A. (2005). Anthropological and Sociological Perspectives on the Study of Children. In Greene S.M, Hogan D.M. (Eds). Researching Children's Experiences: Approaches and Methods, London: Sage.

Dhakal, H. (2010). Participatory school governance: Children in decision making in the public school of Nepal. Participatory school governance in Nepal.

Fielding, M. (2001). Students as radical agents of change, Journal of Educational Change, 2(2), 123-41.

Hill, M. (1995). Young people's views of social work and care services. Child Care in Practice, 2, 49-59.

Inter-Agency Working Group on Children's Participation (IAWGCP). (2008). Children as active citizens. A policy and programme guide. Commitments and obligations for children's civil rights and civic engagement in East Asia and the Pacific. Bangkok. Retrieved from: http://resourcecentre.savethechildren.se/sites/default/files/documents/2035.pdf

Jaeger, P., \& Zsolnai, J. (2004). Research Training Program in Primary Schools of Hungary. Paper presented at The University of Vesprem. Hungary.

James, A., Jenks, C. \& Prout, A. (1998). Theorizing Childhood. Cambridge: Polity Press. Johnson, G. A. (2011). A child's right to participation: Photovoice as methodology for documenting the experiences of children living in Kenyan orphanages. Visual Anthropology Review, 27(2), 141-161.

Kellett, M. (2005). Children as active researchers: a new research paradigm for the $21^{\text {st }}$ century? ERSC, UK. Retrieved from: http://oro.open.ac.uk/7539/1/

Kress, G. (1997). Before writing: Rethinking the paths to literacy. London: Routledge. Lansdown, G. (2005). Can You Hear Me? The Rights of Young Children to Participate in Decisions Affecting Them. Working Paper 36 in Early Childhood Development. The Hague, Netherlands: Bernard van Leer Foundation. 
MacNaughton, G. (2001a). Dolls for equity: foregrounding children's voices in learning respect and unlearning unfairness. Folio, 5, 27-30.

MacNaughton, G. (2001b). Silences and subtexts in immigrant and non-immigrant children's understandings of diversity. Childhood Education, 78, 30-36.

MacNaughton, G. (2001c). Blushes and birthday parties: telling silences in young children's constructions of 'race'. Journal of Australian Research in Early Childhood Education, 8, 41-51.

MacNaughton, G., Hughes, P. \& Smith, K. (2007). Young Children's Rights and Public Policy: Practices and Possibilities for Citizenship in the Early Years. Children \& Society, 21,458-469.

Winstone, N. (2014). Eliciting rich dialogue through the use of activity-oriented interviews: Exploring self identity in autistic young people. Childhood, 21(2), 190-206. 